\title{
Antiviral Activity of Extracts of Plocamium Brasiliense and Plocamium Cartilagineum at in Vitro Replication of Human Immunodeficiency Virus Type 1
}

\begin{abstract}
Ingrid De Barcelos Oliveiraa ${ }^{1,4,5}$, Rainiomar Raimundo Fonseca ${ }^{2,4}$, Claudio Cesar Cirne-Santos ${ }^{1,3,4}$, Caroline de Souza Barros ${ }^{1,3,4}$, Valeria Launeville Teixeira ${ }^{2,3,4}$, Izabel Christina Nunes de Palmer Paixao ${ }^{1,3 *}$
\end{abstract}

${ }^{1}$ Department of Celular and Molecular Biology, Laboratory of Molecular Virology, Federal Fluminense University, Brazil

${ }^{2}$ Department of Marine Biology, Laboratory of Marine Natural Products, Institute of Biology, Federal Fluminense University, Brazil

${ }^{3}$ Post-graduate Program in Science and Biotecnology, Federal Fluminense University, Brazil

${ }^{4}$ Post-graduate Program in Chemistry, Institute of Chemistry, Federal Fluminense University, Brazil

*Corresponding author: Izabel Christina Nunes de Palmer Paixão, Department of Celular and Molecular Biology, Laboratory of Molecular Virology, Institute of Biology, Federal Fluminense University, Niteroi, RJ, 24020-150, Brazil.
Received Date: September 23, 2019

Published Date: September 30, 2019

\section{Abstract}

The marine macroalgae Plocamium brasiliense and P. cartilagineum are species characterized by the production of halogenated metabolites. For the present study, algae were collected from the coast of Rio de Janeiro, Brazil and the Cape Verde Archipelago, in the African continent. The raw extracts of the algae were prepared in different solvents exhaustively and fractionated for later isolation and structural elucidation of the major substances to compare the chemical profile of the two species of red algae. The hydroalcoholic extracts of both species showed antiviral activity against the HIV-1 virus and were the least cytotoxic. The dichloromethane extract of the P.brasiliense macroalgae had the lowest antiviral effect among the others tested. Virucidal activity, however, was not observed. Based on NMR, IR and literature data, it was found that the antiviral result was attributed to the sulfated polysaccharides in the red macroalgae. Both macroalgae show potential to be exploited by marine biotechnology, based on the results found in this work.

Keywords: HIV-1; Seaweed; P. cartilagineum; Halogenated monoterpenes; Allelopathy

\section{Introduction}

The human immunodeficiency virus type-1 (HIV-1) is a Lentivirus that infects CD4+ T lymphocytes, monocyte/ macrophages and dendritic cells, using the CD4 molecule and the chemokine receptors CCR5 or CXCR4 to enter the target cells [1]. HIV-1 is the etiological agent of the acquired immunodeficiency syndrome (AIDS) and has become a serious threat to global public health in the last decades [2-5].

The inhibition of HIV-1 life cycle constitutes one of the major purposes of the antiretroviral therapy (HAART). Several steps of the viral growth cycle have been studied as potential target for drugs design. Although combination antiretroviral therapy led to a major reduction in HIV-related mortality and morbidity, HIV still cannot be cured. Furthermore, the use of these drugs has been limited by the lack of patient's compliance to the treatment due to side effects and toxicity of drugs, besides rapid emergence of resistant virus strains to the currently approved AIDS treatments [6-8]. For this reason, the search for new antiviral compounds is crucial for the fight against AIDS. Products derived from natural sources, such as bacteria, fungi, plants and marine flora and fauna have displayed several biological activities [9]. Specifically, marine algae represent one of the richest sources of bioactive compounds, and algae-derived products are increasingly used in medical and biochemical research [10].

The genus Plocamium J.V. Lamouroux is characteristic of a cold temperate climate, with a few species, such as P. hamatum J. Agardh and P. brasiliense (Greville) Howe \& Taylor, occurring in tropical areas. 107 species have been described for the genus, of which only 44 are recognized [3]. Today data are found in the literature on metabolites isolated from marine macroalgae, with definite biological actions, such as the following examples, anti- 
inflammatory [4,5], antiviral [6], antileishmaniasis [7], antioxidants [8], allelopathic [9], against snake venom [10, 11].

In the present study, the inhibitory effects of different organic extracts (n-Hexane (HE); Dichloromethane (DC); Ethyl acetate (EA) and Hydroalcoholic (HA)) obtained from P. brasiliense and $P$. cartilagineum macroalgae were presented with potential sources of antiviral substances against the HIV-1 virus.

\section{Material and Methods}

Cytotoxicity evaluation: MT-2 cells (2.0 x 105 cells/well) were exposed to different concentrations of extracts of $P$. brasiliense and P. cartilagineum for $72 \mathrm{~h}$. After incubation, cell viability was assessed by an MTT method [11]. The 50\% cytotoxic concentration (CC50) was defined as the concentration $(\mu \mathrm{M})$ that reduced viability by $50 \%$ when compared to untreated controls.

Anti-HIV assay: For the anti-HIV-1 activity screening, peripheral blood mononuclear cells (PBMCs) from healthy human donors were obtained by density gradient centrifugation (Histopaque; Sigma, St. Loius, USA) from buffy coat preparations. PBMCs were ressuspended in RPMI 1640 (LGO Bio, São Paulo, Brazil), supplemented with 10\% FBS (Hyclone, Logan, USA), penicillin and streptomycin (Cultilab, São Paulo, Brazil), $2 \mathrm{mM}$ glutamine and 10mM HEPES (Sigma, St. Louis, USA), stimulated with $5 \mathrm{mg} / \mathrm{ml}$ of phytohemagglutinin (PHA; Sigma, St. Lous, USA) for two to three days, and further maintained in culture medium containing $5 \mathrm{U} / \mathrm{ml}$ of recombinant human interleukin-2 (Sigma, St. Louis, USA). HIV-1 isolates IIIb (X4-tropic) [12] were used to infect cells. Virus isolates were prepared in PHA-activated PBMCs from human healthy donors.

The screening of in vitro anti-HIV-1 activity was assessed following the procedures described previously [13] with minor modifications. Peripheral blood mononuclear cells (PBMCs) and
MT-2 cells were initially exposed to viral suspensions containing 5-10ng/ml of HIV-1 p-24 Ag during 1-2 h. Cells were washed, resuspended in complete medium, plated in 96-well culture plates (2.0 x 105cells/well) in triplicate, and treated with different concentrations $(\mu \mathrm{g} / \mathrm{mL})$ of extracts. After seven days at $37^{\circ} \mathrm{C}$ in $5 \% \mathrm{CO}_{2}$, viral replication was assessed by measuring the HIV p-24 Ag presence in culture supernatants by an ELISA capture assay (ZeptoMetrix Co., Buffalo, USA).

\section{Results and Discussion}

Cytotoxicity evaluation: the viability of MT-2 cells facing the extracts of Plocamium brasiliense and Plocamium cartilagineum was measured by mitochondrial activity. The extracts less cytotoxic for MT-2 cells were PBHA 242,28 $\mu \mathrm{g} / \mathrm{mL}$ and PCHA $(194,52 \mu \mathrm{g} / \mathrm{mL})$, derived from hydroalcoholic extraction from $P$. brasiliense and $P$. cartilagineum, respectively (Table 1).

Table 1: Cytotoxicity of raw extracts from $P$. brasiliense and $P$. cartilagineum in MT-2 cells. PBHE $-n$-hexan extraction $P$. brasiliense; PBDC - dichloromethane extraction $P$. brasiliense; PBEA - ethyl acetate extraction P. brasiliense; PBHA - hydroalcoholic extraction P. brasiliense; PCHE - $n$-hexan extraction $P$. cartilagineum; PCDC - dichloromethane extraction $P$. cartilagineum; PCEA - ethyl acetate extraction $P$. cartilagineum; PCHA - hydroalcoholic extraction P. cartilagineum. *Literature data [14].

\begin{tabular}{|c|c|}
\hline Extracts & CC50 $(\mu \mathrm{g} / \mathrm{mL})$ \\
\hline PBHE & $86 \pm 1,00$ \\
\hline PBDC & $44,62 \pm 22,21$ \\
\hline PBEA & $89,59 \pm 18,04$ \\
\hline PBHA & $242,28 \pm 26,45$ \\
\hline PCHE & $35 \pm 15,08$ \\
\hline PCDC & $39 \pm 19,95$ \\
\hline PCEA & $30,88 \pm 4,25$ \\
\hline PCHA & $194,52 \pm 32,13$ \\
\hline AZT* & 2,67 \\
\hline
\end{tabular}

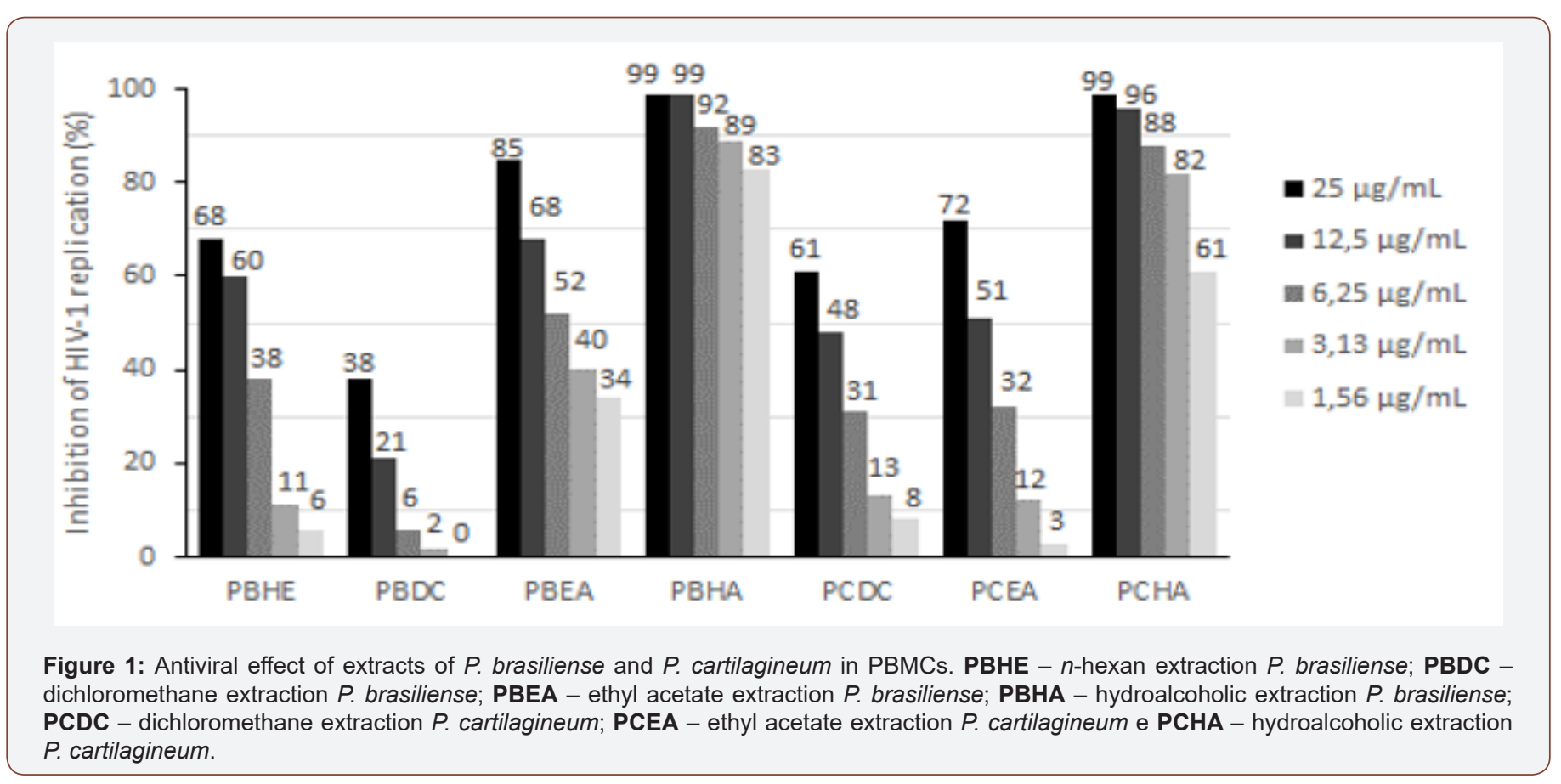




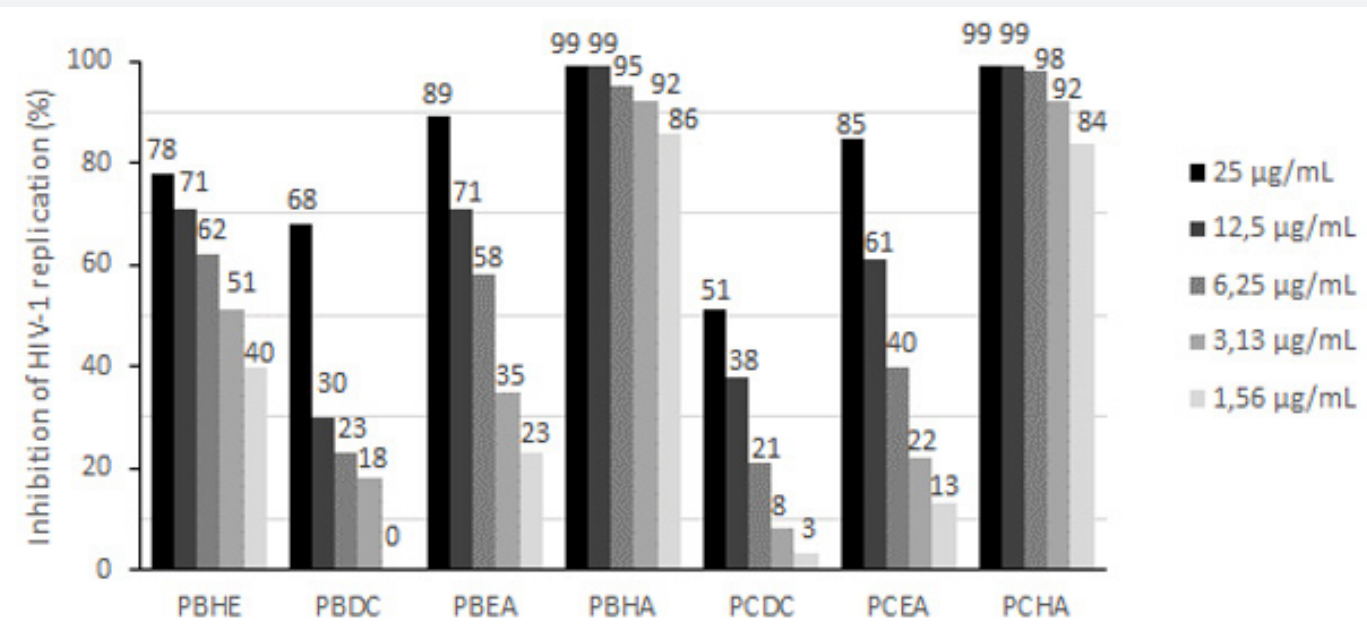

Figure 2: Antiviral effect of extracts of $P$. brasiliense and $P$. cartilagineum in MT-2 cells. PBHE $-n$-hexan extraction $P$. brasiliense; PBDC dichloromethane extraction P. brasiliense; PBEA - ethyl acetate extraction P. brasiliense; PBHA - hydroalcoholic extraction $P$. brasiliense; PCDC - dichloromethane extraction P. cartilagineum; PCEA - ethyl acetate extraction $P$. cartilagineum e PCHA - hydroalcoholic extraction $P$. cartilagineum.

Anti-HIV assay: antiviral activity was assessed in PBMCs and MT-2 cells. Both types of cell show similar results, which presented higher values of percentage of inhibition for PBHA, hydroalcoholic extraction of $P$. brasiliense Figure 1 and PCHA, hydroalcoholic extraction of $P$. cartilagineum Figure 2, reaching up to $99 \%$ of inhibition in vitro replication of virus to both extracts.

Marine natural products have demonstrated pharmacological activities against a large number of pathogens, including HIV-1 2005, 2006. Natural compounds capable of inhibiting the HIV1 virus in some way have been studied in recent years, such as: sulfated polysaccharides (dextran sulfate, pentosan polysulfate, heparin) from red algae Aghardhiella tenera that inhibit viral replication 1997, 2000a; Sulfated sterols, isolated from the sponge Xestospongia sp., haplosamates A and B, inhibit HIV integrase, while another sulphated sterol, clatsterol, isolated from the algae Clathria sp., inhibits reverse transcriptase activity 1999, 2001, 2005, diploretohydroxycarmalol, a carmalol derivative isolated from the brown seaweed Ishige okamurae, has shown inhibitory effects against HIV-1 reverse transcriptase and integrase 2006, 2010. The two algae studied in this work, Plocamium brasiliense and Plocamium cartilagineum, have several described biological activities, but no anti-HIV-1 activity has been reported yet. This is important because the extracts used in this study may represent a source for the study of compounds or molecules with potential antiviral activity.

In Figure 1 we can see that in peripheral blood mononuclear cells [PBMCs) the results showed significant inhibitory effect mainly by PBHA - hydroalcoholic extraction P. brasiliense, followed by PCHA hydroalcoholic extraction P. cartilagineum. These data demonstrate an important effect on infected primary cells that represent a very representative cell profile. In Figure 2, the effects were observed in MT-2 lineage cells demonstrating an effect similar to that seen in PBMCs demonstrating reproducibility of these assays.

\section{Conclusion}

The present study showed antiviral activity of extracts derived from red algae $P$. brasiliense and P. cartilagineum against HIV-1 while presented low cellular toxicity. Both extracts PBHA and PCHA were less toxics to the cells in comparison to the other extracts tested and to the reference drug AZT. It can be observed potent inhibition face to HIV-1 replication, up to $99 \%$ in two of extracts tested. Further studies about mechanism of action and enzyme inhibition are needed to asses in which steps of replicative cycle the extracts act [14].

\section{Acknowledgements}

This study was financed in part by the Coordenação de Aperfeiçoamento de Pessoal de Nível Superior - Brasil [CAPES) Finance Code 001

\section{Conflict of Interest}

The authors declare that the research was conducted in the absence of any commercial or financial relationships that could be construed as a potential conflict of interest.

\section{References}

1. Berger EA, Murphy PM, Farber JM (1999) Chemokine receptors as HIV-1 coreceptors: roles in viral entry, tropism, and disease. Annu Rev Immunol 17: 657-700.

2. Starr-Spires LD, Collman RG (2002) HIV-1 entry and entry inhibitors as therapeutic agents. Clin Lab Med 22: 681-701.

3. Stevenson M (2003) HIV-1 pathogenesis. Nat Med 9: 853-860.

4. Barré-Sinoussi F, Chermann JC, Rey F, Nugeyre MT, Chamaret S et al. (1983) Isolation of a T-lymphotropic retrovirus from a patient at a risk for acquired immune deficiency syndrome (AIDS). Science 220(4599): 868-871.

5. Zagury D, Bernard J, Leibowitch J, Safai B, Groopman JE, et al. (1984) HTLV-III in cells cultured from semen of two patients with AIDS. Science 226(4673): 449-451. 
6. Torres TS, Macedo WP, Pedrosa LF (2008) Synthesis and anti-HSV-1 in vitro activity of new phosphoramidates with 4-oxoquinoline and phtalimidic nuclei. Letters in Drug Design Discovery 5: 644-650.

7. Santos FC, Abreu P, Castro HC (2009) Synthesis, antiviral activity and molecular modeling of oxoquinoline derivatives. Bioorganic \& Medicinal Chemistry 17: 5476-5481.

8. Boone LR, Koszalka GW (2010) Antiretroviral drug development for HIV: challenges for the future. Curr Opin Investig Drugs 11(8):863-67.

9. Diaz-Marrero AR, Cueto M, Dorta E, Juana Roviros, Aurelio San-Martín, et al. (2002) New halogenated monoterpenes from the red alga Plocamium cartilagineum. Tetrahedron 58: 8539-8542.

10. Ghosh T, Chattopadhyay K, Marschall M (2009) Focus on antivirally active sulfated polysaccharides: From structure-activity analysisto clinical evaluation. Glycobiology 19(1): 2-15.

11. Mosmann T (1983) Rapid colorimetric assay for cellular growth and survival: application to proliferation and cytotoxicity assays. J Immunol Methods 65(1-2): 55-63.

12.

a) Deffin GF, Kendall JD (1948) J Am Chem Soc 70: 893. b) Snyder HR, Freier HE, Kovacic P, Heyningen EMV (1947) J Am Chem Soc 69: 371

c) Lauer WM, Arnold RT, Tiffany B, Tinker H (1946) J Am Chem Soc 68: 1268.

d) Ramsey VG, Cretcher LH (1947) J Am Chem Soc 69: 1659

e) Riegel B, Lappin GR, Adelson BH (1946) J Am Chem Soc 68: 1264

f) Jackson RI, Albisetti CJ, Jr Dodson RM, baker RH (1946) J Am Chem Soc 68: 1264

g) Roberts RB (1948) J Am Chem Soc 70: 277

13. Souza TM, Cirne-Santos CC, Rodrigues DC, Abreu CM, Tanuri A, et al. (2008) The compound 6-chloro-1,4-dihydro-4-oxo-1-(beta-Dribofuranosyl) quinoline-3-carboxylic acid inhibit HIV-1 replication by targeting the enzime reverse transcriptase. Curr HIV Res 6(3):209-217.

14. Harms A (2007) Non-nucleoside HIV reverse transcriptase inhibitors. In: Johnson D.S., Li J.J. eds. The art of drug synthesis. New Jersey: John Wiley \& Sons pp. 276. 